\title{
Questionnaire Based Mental Health Survey During Covid 19 Outbreak
}

\author{
Mallam. Meghana Goud*1, Dr. Ch. B. Praveena Devi² \\ 1. Pharm D $3^{\text {rd }}$ Year, Joginpally B R Pharmacy College, Moinabad, Hyderabad, Telangana, India. \\ 2. Assistant Professor, Joginpally B R Pharmacy College, Moinabad, Hyderabad, Telangana, India. \\ *Corresponding author's E-mail: mallammeghana1998@gmail.com
}

Received: 18-05-2021; Revised: 24-07-2021; Accepted: 30-07-2021; Published on: 15-08-2021.

\begin{abstract}
The study is conducted among 279 people in Telangana and Andhra Pradesh. This study is done during the lockdown collected the information by having a source of google form survey. This google form is created based on the GAD 7 questionnaire which consists of 7 questions related to mental health during this covid 19 pandemic. Most probable results were collected and listed out. Throughout the planet, the general public is being informed about all the physical effects of SARS COV 2 infection and steps taken to require and to stop the exposure to coronavirus and also to manage symptoms of COVID 19. However, the consequences of this pandemic on the person's psychological state haven't been studied, and still not known. As the efforts are focused on understanding epidemiology, clinical features, transmission patterns, and management of the COVID 19 outbreak, there has been little or no concern expressed over the consequences on one's psychological state and on strategies to stop stigmatization. People's behaviour may greatly affect the pandemics dynamic by altering the severity, transmission, disease flow and repercussions. This situation requires raising awareness publicly, which may be helpful to affect this calamity. This clinical study provides in depth overview of the consequences of the COVID 19 outbreak on the psychological state of an individual.
\end{abstract}

Keywords: COVID 19, Mental health, Anxiety, CNS effect, GAD -7.

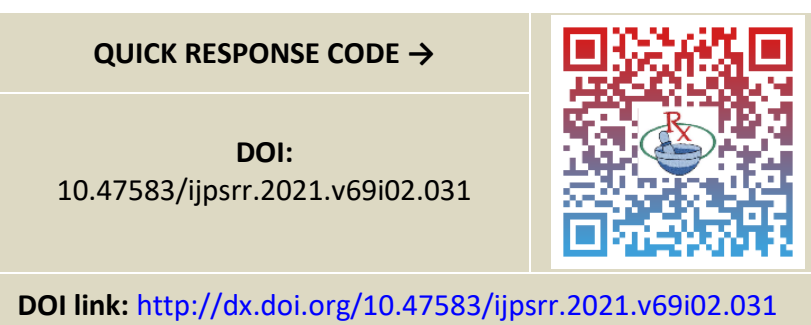

\section{INTRODUCTION}

have collected some information by the survey conducted through google forms and had a questionnaire which consists of 7 questions regarding covid and mental health based on the GAD 7 score interpretation is done and calculated

SARS-COV2 is the causal agent of Covid 19, a potentially lethal disease that is a major public health problem around the world. And, based on the large number of people affected as a result of their exposure to the wet animal market in Wuhan, China. ${ }^{1}$

Corona virus is one among the main pathogens that primarily targets the human respiratory system. Previous outbreaks of coronavirus (covs) include the serve acute respiratory syndrome (SARS)-CoV and the Middle East respiratory syndrome (MERS)-CoV which have been previously characterized as agents that are a great public health threat. ${ }^{1}$

\section{Impact of Covid 19 Pandemic in People}

The potential impact of the COVID 19 pandemic on population psychological state is of accelerating global concern. We examine changes in adult psychological state in INDIA population before and through the lockdown COVID 19, caused by severe acute respiratory syndrome coronavirus 2 , and measures taken to curb its spread have profoundly affected every aspect of day-to-day life round the world. The INDIA government's lockdown, implemented on social contact, on the power for several people to figure and greatly reduced access to services. ${ }^{2}$

\section{Covid 19 Pandemic in People \& Effect on CNS}

As the number of patients with COVID-19 is increasing worldwide, it's necessary to worry on the importance of the atypical clinical presentations (including those associated with the nervous system) of COVID-19 infection, since they could be the initial manifestations. Patients with COVID-19 infection should be evaluated early for neurological symptoms. Timely analysis of spinal fluid and early appropriate management of infection-related neurological complications could be the key to enhance the prognosis of critically ill patients. ${ }^{2}$

Since health-care providers might under-recognize these cases with atypical presentations, and these patients may represent a hidden source of the spread of the virus, we believe that literature on this regard should be sent by the international and native health committees to all or any health-care providers during this COVID -19 pandemic, to form sure that each one providers are well informed and conscious of these cases. Moreover, awareness campaigns addressing this issue should be directed to the population. ${ }^{2}$ 


\section{METHODS AND MATERIALS}

This study has been conducted in lockdown and written informed consent and was obtained from all the 279 participants respectively before inclusion in this study.

Informed Consent By Participants

\section{9 responses}

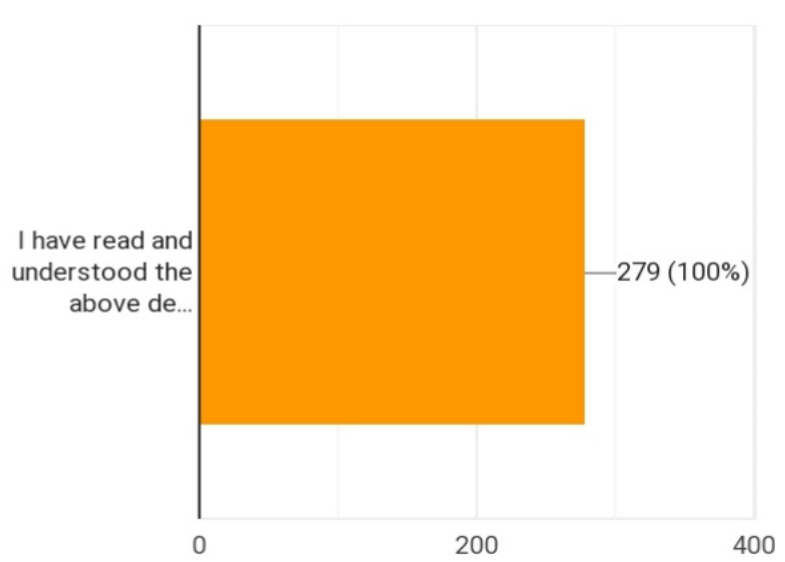

\section{Subjects and Study Area}

This clinical study is conducted in Hyderabad, Andhra Pradesh among the youth and adults of different areas. And also, students from different IT sectors, software's, and also the study is mainly conducted among few volunteers of JBRPC College.

Participants in this study were female and male of different ages.

\section{Sample}

In this clinical study / survey conducted in a total of 279 subjects. Among these subjects $67.4 \%$ are female and $32.3 \%$ were males of different age groups. Age groups involved in this clinical study are:

\begin{tabular}{|c|c|}
\hline Age group & \% of participants \\
\hline $18-24$ yrs. & $85.3 \%$ \\
\hline $25-44$ yrs. & $9.3 \%$ \\
\hline $45-64$ yrs. & $5 \%$ \\
65 yrs. and higher & $3 \%$ \\
\hline
\end{tabular}

The sampled people / subjects in this study are of different courses of their study like they include some students at different pharmacy colleges. IT professionals etc.

Demographic data of the subjects were collected which includes age, gender

\section{Demographic Details of Users}

In this study among 279 volunteers, out of which there are $32.3 \%$ male and $67.4 \%$ female, of different age groups

\section{Age groups}

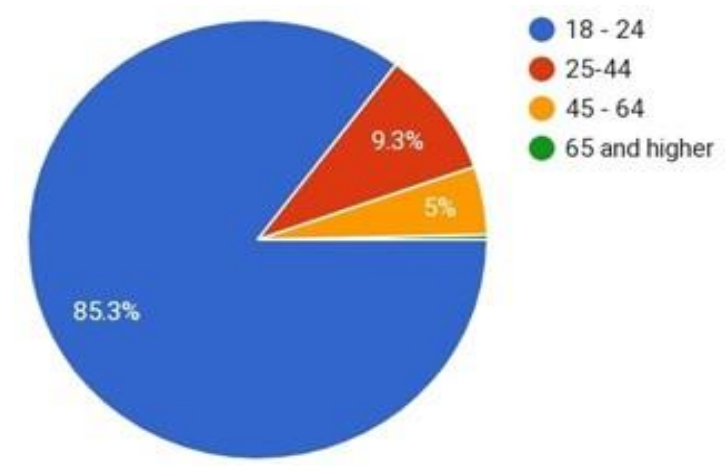

The age groups of different ages including 18-24, 25-44, 45-64, 65 and higher are collected. And they belong to telangana and andhrapradesh of different working sectors.

\section{Genders}

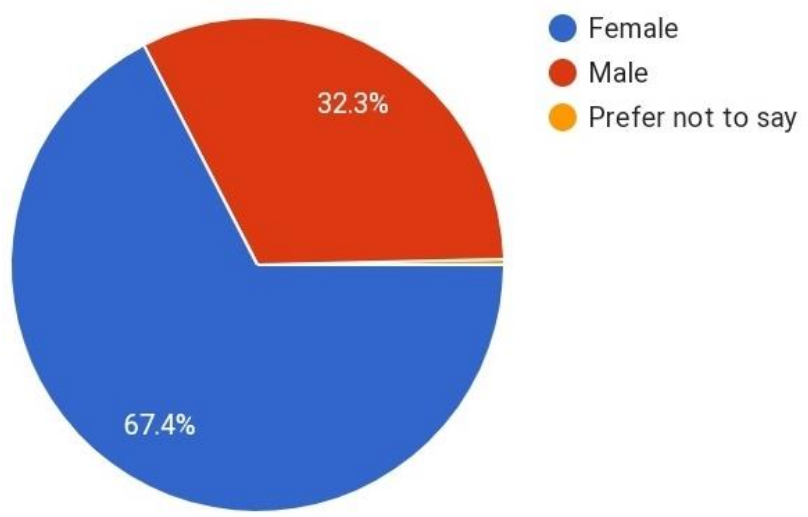

This clinical study include females and males. Female of $67.4 \%$ and males of $32.3 \%$ of different age groups as mentioned above.

\section{Methods of Data Collection and Measures}

In this clinical study a questionnaire based mental health survey is done during the covid 19 outbreak.

GAD- 7 \{ generalised anxiety disorder -7$\}$ scale is used to acess the anxiety symptoms of the subject. ${ }^{3}$

This survey/ questionnaire of the study is divided into 3 sections, in which the first section includes the purpose of study and also informed consent for the participants.

And the second section consists of the demographic details of the subject which include age group - under which age group of the subject belongs to and also gender - to which gender the subject belongs to male or female or prefer not to say.

The third section consists of the heart of the study that is \{ GAD - 7\} generalised anxiety disorder 7 which typically consists of 7 questions it reflects the frequency of symptoms how the symptoms were during the preceding 2 weeks of period. ${ }^{3}$

The GAD - 7 approximately requires less than two minutes to check each symptom, and the following will be the response options in GAD 7 
“ NOT AT ALL” " SEVERAL DAYS” “ OVER HALF OF THE DAYS" "NEARLY EVERYDAY " and these responses can be recorded as according to the severity $0,1,2$, or 34
And the complete data of the responses from the subjects is collected and also attached.

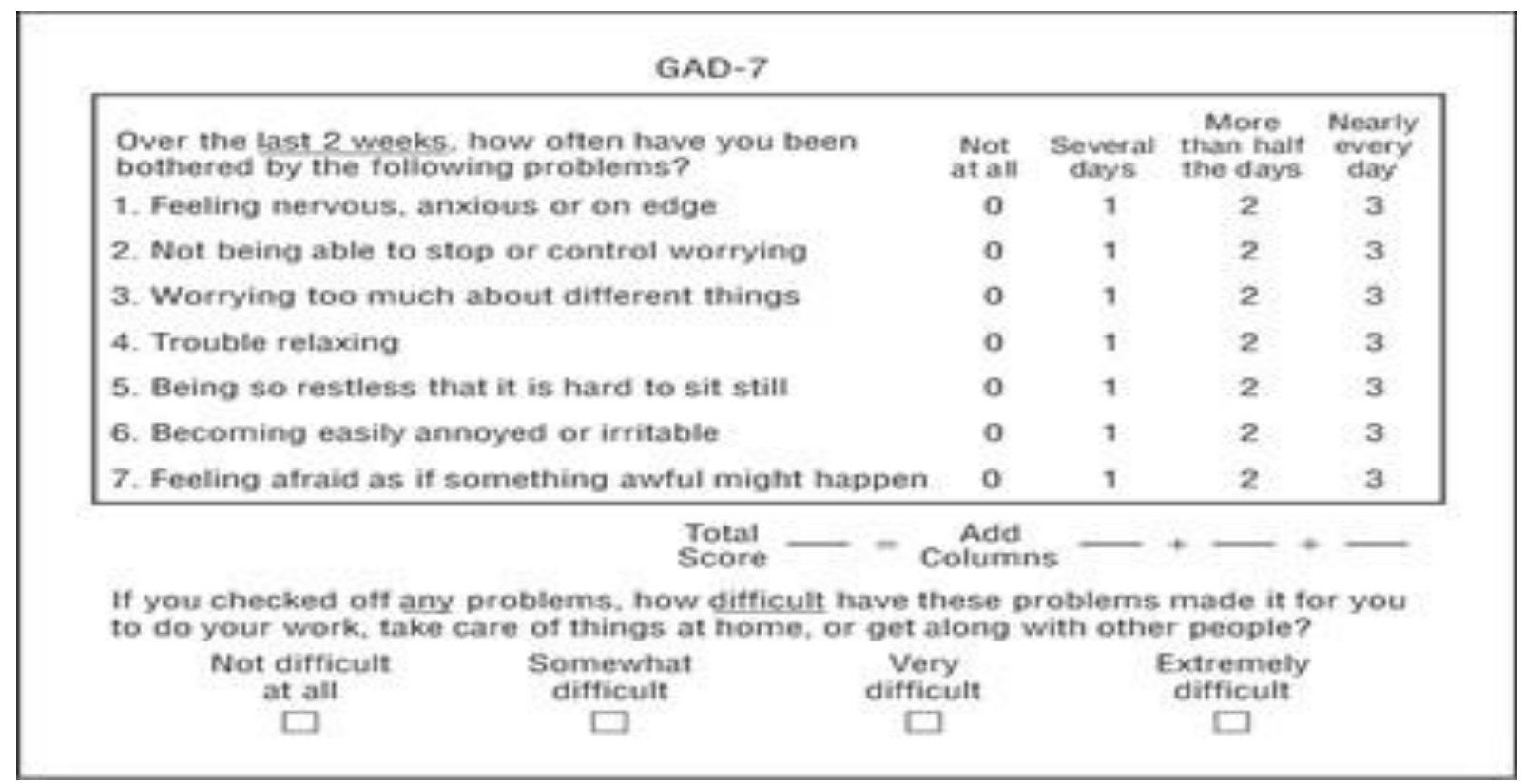

\section{RESULTS AND DISCUSSION}

The major psychological issues reported were mainly stress, anxiety, depression, insomnia, anger and fear. Geriatric and paediatrics, frontline workers are the people with existing psychological illness were among the most vulnerable during this study. ${ }^{5}$

COVID 19 related suicides have also been increasing commonly. Globally, measures are taken to deal with the psychological issues through the utilization of guidelines and intervention strategies, telepsychiatry consultations, toll free number specific for psychological and behavioral issues are issued by the government of India. ${ }^{5}$

\section{People With Preexisting Mental IIIness}

It is known that at the increase of a plague, generally people with the pre-existing psychological conditions are among the foremost affected. The explanations include social stigmatization, risk of infection, low priority to morbidities of psychological state etc. these including cognitive impairment, little awareness of risk and diminished efforts regarding the personal protection in patients, also as confined conditions in psychiatric wards could increase the vulnerability of people with presenting psychological illness during the COVID 19 pandemic. ${ }^{6}$

Discrimination and fear of social isolation thanks to social distancing worsened by the consequences of the COVID 19 pandemic wandering unsound people are at major risk of contracting illness secondary to compromised immune status. Relapse and exacerbation of severe psychological conditions secondary to lockdown and unavailability of psychotropic in rural pharmacies also can pose hurdle to the health care system. ${ }^{6}$

\section{Impact on frontline workers}

The frontline workers including doctors, nurses, community doctors, sanitation workers, policemen, and other volunteers across the planet are in a completely unprecedented situation, having to form impossible decisions and work under extreme pressures. Working under stressful conditions with scarce resources affect not just their personal and family life, but also place them during a situation of ethical injury, causing psychological state difficulties. These symptoms can contribute to the even suicidal ideation aside from being at high risk of infection, battlefront healthcare workers including doctors are subject to stigma by community and neighborhoods. Many instances of eviction and harassment from home owners, violence on duties against doctors at the workplace, social isolation, and discrimination are reported. ${ }^{6}$

\section{Impact on young adults and college students}

In the clinical study conducted among the students and teenagers of Telangana and Andhra Pradesh the pre lockdown learning of youngsters and adolescents predominantly involved one to one interaction with their mentors and peer groups. Unfortunately, the nationwide closures of faculties and colleges have negatively impacted over $91 \%$ of the people in Telangana and Andhra Pradesh. The house of confinement of youngsters and adolescents is related to uncertainty and anxiety which is due to disruption in their education, physical activates and opportunities for socialization. Some children have expressed lower levels of affect for not having the ability to play outdoors, not meeting friends and not getting engaged within in person school activities. These children became clingier, attention seeking and more hooked into their parents thanks to the future shift in their routine. It's 
presumed that children might resist going to schools and colleges after the lockdown gets over and should face difficulty in establishing rapport with their mentors after faculty reopen. ${ }^{6}$

\section{Younger Adults are More Likely to Report Symptoms of Anxiety and/or Depressive Disorder During the COVID-19 Pandemic}

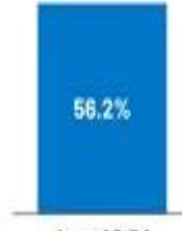

Ages $18 \cdot 24$

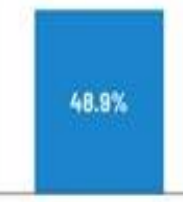

Ages $25-49$

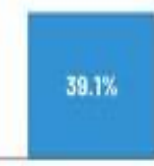

Ages 50-64

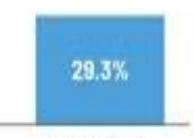

Ages $65+$
Consequently, the constraint of movement imposed on them can have an extended term negative effect on their overall psychological wellbeing. A study found that older adolescents and youth are anxious regarding cancellation of examinations, exchange programs and academic it's also found that among youth social distancing is viewed primarily as a social responsibility and it's followed more sincerely if motivated by prosaically reasons to stop others from getting sick confinement reception children's increased use of internet and social media predisposes them to use internet compulsively, access objectionable content and also increases their vulnerability for getting bullied or abused Worst of all, during lockdown when schools, when legal and preventative services don't functioning fully, children are rarely during a position to report violence, abuse and harm if they themselves have abusive homes ${ }^{7}$

\section{GAD 7 \{Generalized Anxiety Disorder 7\}}

The 7 item generalized mental disorder scale. The GAD 7 may be a 7 item self-report measure designed to screen for the presence of GAD 7 and to live the severity of symptoms following DSM - 4 criteria. The GAD 7 asks how often the participants are bothered by anxiety symptoms within the past 2 weeks. $^{7}$

A score of 10 greater on the GAD 7 represents an inexpensive cut point for identifying cases of GAD. Cut points of 5,10 , and 15 could be interpreted as representing mild, moderate and several levels of hysteria on the GAD 7, almost like levels of depression on the PHQ-9. ${ }^{7}$

The PHQ-9 and GAD-7 are designed to facilitate the popularity for depressive disorders and anxiety disorders respectively. These are the national standard measures routinely employed by GP'S, therapists and psychiatrists as screening tools. The scoring for both measures helps people to determine how severe the difficulty is. ${ }^{8}$

\section{Scoring GAD 7 Anxiety Severity}

\section{GAD 7 Question Wise Results Via Graphs}

Figure 1

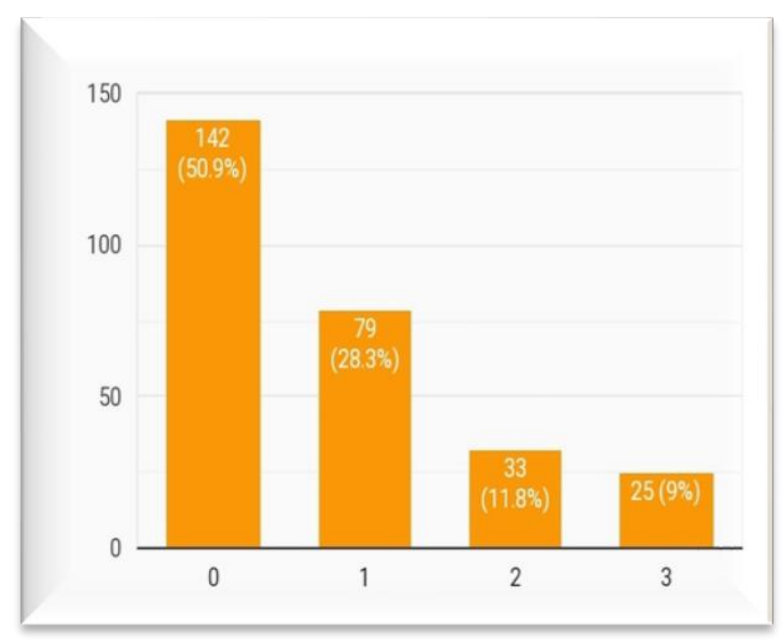

Feeling Nervous, Anxious, Or On Edge?

\section{Not being able to stop or control worrying}

Figure 2

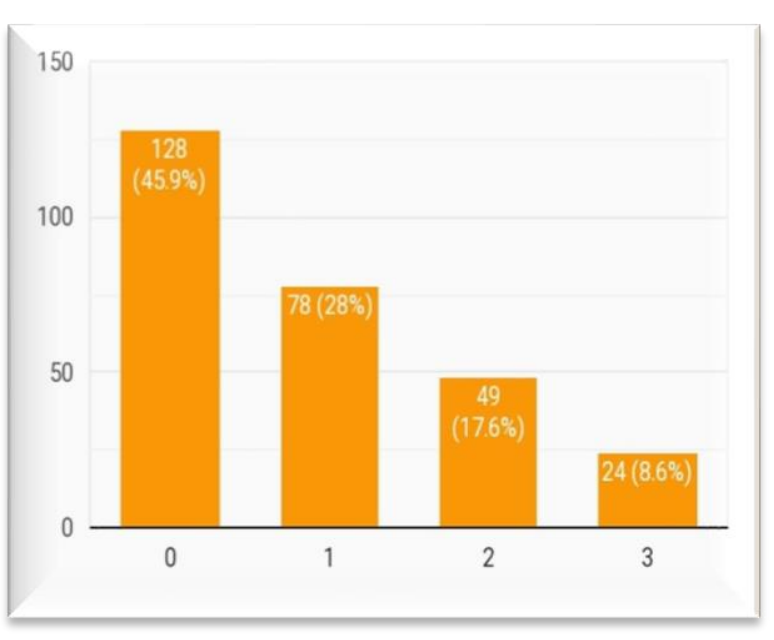

\section{Worrying Too Much About Different Things}

Figure 3

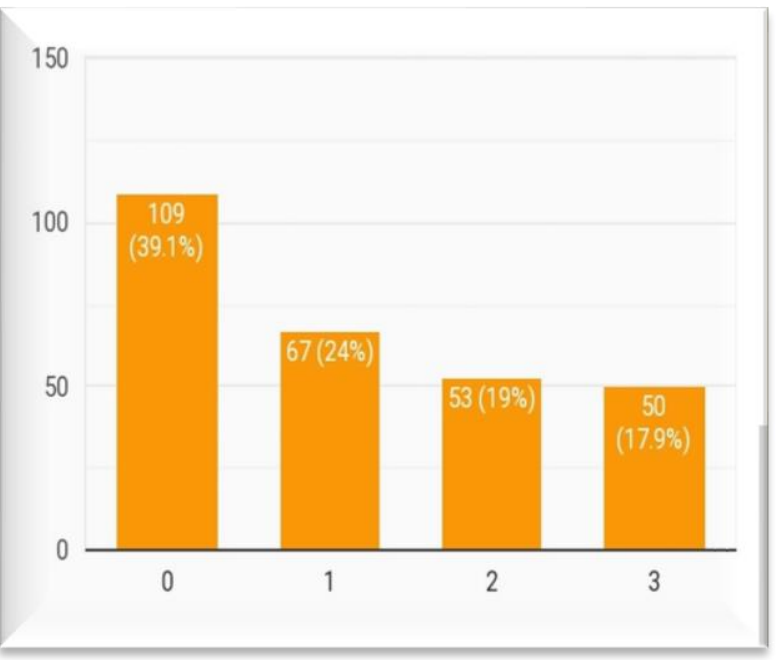




\section{Trouble relaxing}

Figure 4

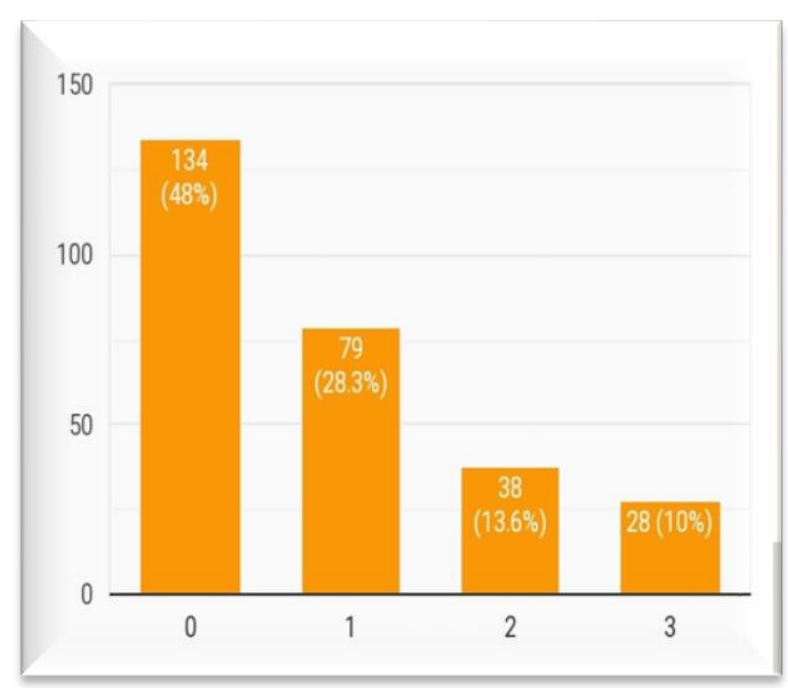

\section{Being so restless that it is hard to sit still}

Figure 5

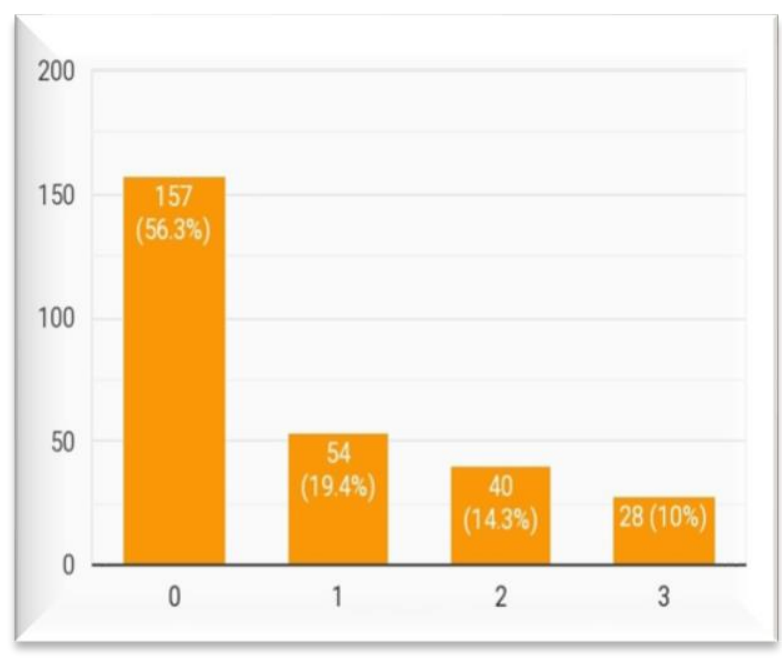

\section{Becoming easily annoyed or irritable}

Figure 6

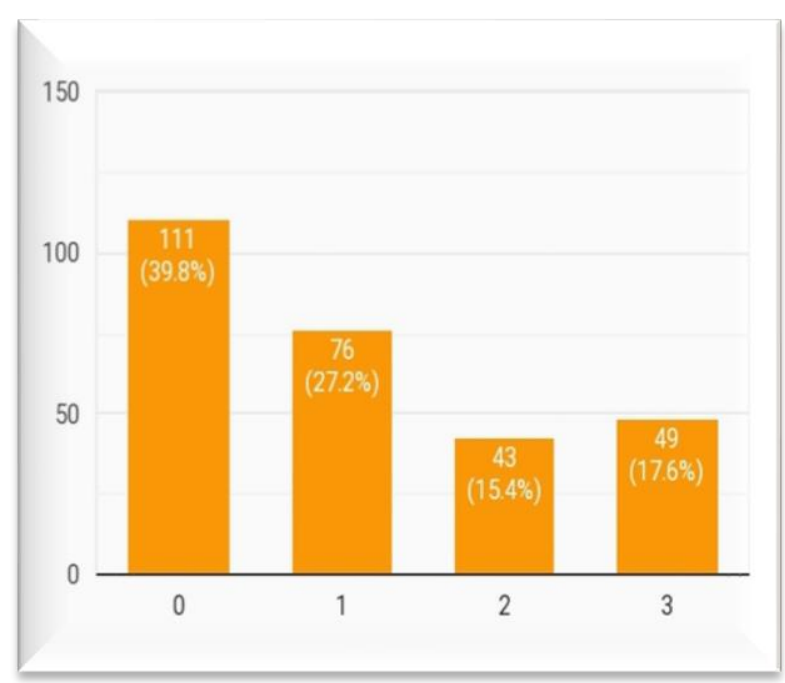

Feeling afraid as if something awful may happen

Figure 7

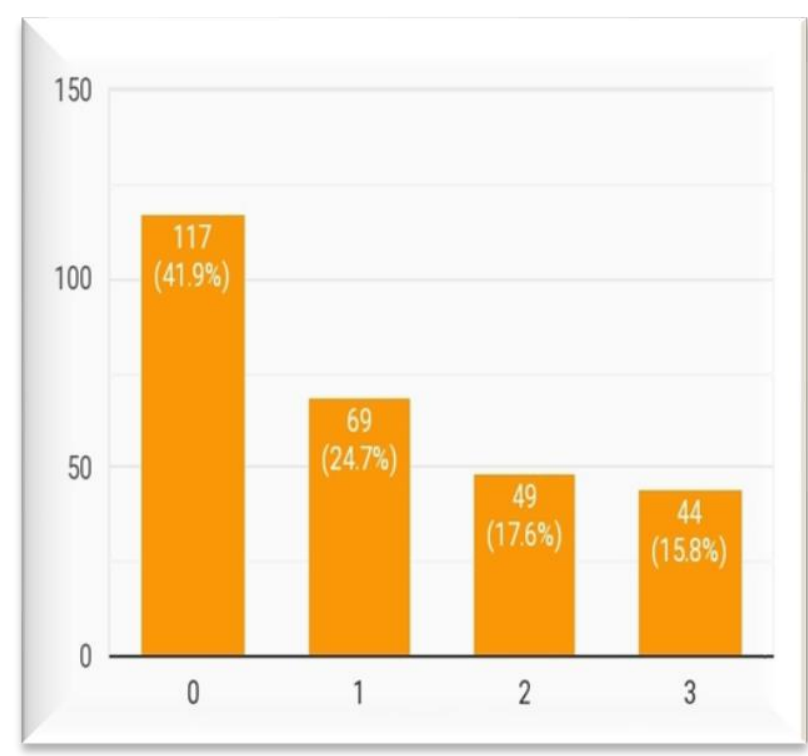

\section{CONCLUSION}

Although the speed of COVID 19 infection among young children and adolescents is low, the strain confronted by them poses their condition as highly vulnerable. crosssectional studies are conducted to research the impact of COVID and lockdown on children and youth. The results of the study shows that the character and extent of this impact depend upon several vulnerability factors like the age, educational status, pre-existing psychological state condition, being economically underprivileged or being quarantined thanks to fear of infection. This study show that young children show more clinginess, disturbed sleep, nightmares, poor appetite, inattentiveness, and significant separation problems. The School and activity centres are examples of containment methods. Closures for lengthy periods of time expose children and teens to the damaging consequences of loneliness, worry, and uncertainty on educational, psychological, and developmental achievements. Most usage of internet gaming and social media puts them at higher risk. Children and adolescents with psychological state conditions aren't wont to variation within the environment receive training, therapy, and other treatments are at higher risk of being derailed from therapy and special educations. Economically underprivileged children are particularly susceptible to exploitation and abuse hence there might be an exaberation in symptoms and behavioural problems. Economically underprivileged children are particularly susceptibile to exploitation and abuse Children quarantined are at high risk for developing higher risk for mental health related challenges. ${ }^{9}$

There is a requirement to ameliorate children and adolescents access to psychological state services by using both face to face also as digital platforms. For this collaborative network of oldsters, psychiatrists, psychologists, paediatricians, community volunteers, and 
NGOs are required there's a requirement for psychological state compatibility and be accessible to the general public at large. This is able to be crucial to stop during and postpandemic mental challenges within the most vulnerable and unprivileged section of the society. Prevention, promotion, and interventions such as the general public psychological state system should be the emphasis of the health care system and policies to meet the psychological state needs of the people at large while taking regional contextual elements into account. ${ }^{10}$

\section{REFERENCES}

1. Javed B, Sarwer A, Soto E, Mashwani Z. The coronavirus ( COVID -19) pandemic's impact on mental health. The International Journal of Health Planning and Management. 2020; 35(5) :993-996.

2. Javed B, Sarwer A, Soto E, Mashwani Z. The coronavirus ( COVID -19) pandemic's impact on mental health. 2021.

3. Tiirikainen K, Haravuori H, Ranta K, Kaltiala-Heino R, Marttunen M. Psychometric properties of the 7-item Generalized Anxiety Disorder Scale (GAD-7) in a large representative sample of Finnish adolescents. 2021.

4. Mills S, Fox R, Malcarne V, Roesch S, Champagne B, Sadler G. The psychometric properties of the Generalized Anxiety Disorder-7 Scale in Hispanic Americans with English or Spanish language preference. 2021.

5. Dalal P, Roy D, Choudhary P, Kar S, Tripathi A. Emerging mental health issues during the COVID-19 pandemic: An Indian perspective. 2021.

6. Nidal Moukaddam P, Asim Shah M. Psychiatrists Beware! The Impact of COVID-19 and Pandemics on Mental Health
[Internet]. Psychiatric Times. 2021 [cited 24 June 2021]. Available from: https://www.psychiatrictimes.com/view/psychiatristsbeware-impact-coronavirus-pandemics-mental-health

7. Spitzer R, Kroenke K, Williams J, Löwe B. A Brief Measure for Assessing Generalized Anxiety Disorder. 2021.

8. Löwe B, Decker O, Müller S, Brähler E, Schellberg D, Herzog $W$ et al. Validation and Standardization of the Generalized Anxiety Disorder Screener (GAD-7) in the General Population. 2021

9. Li Z, Ge J, Yang M, Feng J, Qiao M, Jiang R et al. Vicarious traumatization in the general public, members, and nonmembers of medical teams aiding in COVID-19 control. 2021.

10. PMC E. Europe PMC [Internet]. Europepmc.org. 2021 [cited 24 June 2021]. Available from: https://europepmc.org/article/MED/33790558

11. Press D. Neuropsychiatric Disease and Treatment - Dove Press [Internet]. Dovepress.com. 2021 [cited 24 June 2021]. Available from: https://www.dovepress.com/neuropsychiatric-diseaseand-treatment-archive3

12. Löwe B, Decker O, Müller S, Brähler E, Schellberg D, Herzog $W$ et al. Validation and Standardization of the Generalized Anxiety Disorder Screener (GAD-7) in the General Population. 2021.

13. Schäfer S, Sopp M, Schanz C, Staginnus M, Göritz A, Michael T. Impact of COVID-19 on Public Mental Health and the Buffering Effect of a Sense of Coherence. 2021.

Source of Support: The author(s) received no financial support for the research, authorship, and/or publication of this article.

Conflict of Interest: The author(s) declared no potential conflicts of interest with respect to the research, authorship, and/or publication of this article.

For any question relates to this article, please reach us at: editor@globalresearchonline.net New manuscripts for publication can be submitted at: submit@globalresearchonline.net and submit_ijpsrr@rediffmail.com 